\title{
Paternal hyperglycemia in rats exacerbates the development of obesity in offspring
}

\author{
Xiaoqin Shi1,*, Xinyu Li1,*, Yi Hou', Xuemei Cao1, Yuyao Zhang1, Heng Wang1, \\ Hongyin Wang', Chuan Peng ${ }^{1,2}$, Jibin Lij ${ }^{3}$, Qifu $\mathrm{Li}^{2}$, Chaodong Wu${ }^{4}$ and \\ Xiaoqiu Xiao ${ }^{1,2,5}$
}

'Laboratory of Lipid \& Glucose Metabolism, The First Affiliated Hospital of Chongqing Medical University, Chongqing, China

2Department of Endocrinology, The First Affiliated Hospital of Chongqing Medical University, Chongqing, China ${ }^{3}$ Department of Nutrition and Food Hygiene, School of Public Health and Management, Chongqing Medical University, Chongqing, China

${ }^{4}$ Department of Nutrition and Food Science, Texas A\&M University, College Station, Texas, USA ${ }^{5}$ Canada-China-New Zealand Joint Laboratory of Maternal and Fetal Medicine, Chongqing Medical University, Chongqing, China

*(X Shi and X Li contributed equally to this work)

Correspondence should be addressed to X Xiao Email bshaw2001@163.com

\begin{abstract}
Parental history with obesity or diabetes will increase the risk for developing metabolic diseases in offspring. However, literatures as to transgenerational inheritance of metabolic dysfunctions through male lineage are relatively scarce. In the current study, we aimed to evaluate influences of paternal hyperglycemia on metabolic phenotypes in offspring. Male SD rats were i.p. injected with streptozotocin (STZ) or citrate buffer (CB, as control). STZ-injected rats with glucose levels higher than $16.7 \mathrm{mM}$ were selected to breed with normal female rats. Offspring from STZ or CB treated fathers (STZ-O and $\mathrm{CB}-\mathrm{O}$ ) were maintained in the identical condition. We monitored body weight and food intake, and tests of glucose and insulin tolerance (GTTs and ITTs), fasting-refeeding and cold exposure were performed. Expression of factors involved in hypothalamic feeding and brown adipose tissue (BAT) thermogenic activity was performed by realtime PCR and Western blot. Adult STZ-O were heavier than CB-O. Impairment of GTTs was observed in STZ-O compared with CB-O at 22 and 32 weeks of age; ITTs results showed decreased insulin sensitivity in STZ-O. Daily food intake and accumulated food intake during 12-h refeeding after fasting were significantly higher in STZ-O. UCP1 levels were downregulated in BAT from STZ-O at room temperature and cold exposure. Finally, STZ-O rats showed suppressed leptin signaling in the hypothalamus as evidenced by upregulated SOCS3, reduced phosphorylation of STAT3, impaired processing POMC and decreased $\alpha$-MSH production. Our study revealed that paternal hyperglycemia predisposes offspring to developing obesity, which is possibly associated with impaired hypothalamic leptin signaling.
\end{abstract}

\author{
Key Words \\ - diabetic father \\ - hypothalamus \\ - thermogenic capacity \\ - obese offspring
}

() 2017 Society for Endocrinology Printed in Great Britain
Published by Bioscientifica Ltd
Journal of Endocrinology

(2017) 234, 175-186 


\section{Introduction}

In the past decades, the global prevalence of obesity and other metabolic diseases (MS) has dramatically increased in both children and adults (Friend et al. 2013, Jaacks et al. 2016). The disproportionately early-onset of obesity and signs of MS among children and adolescents can be partially explained by Baker's 'Fetal origins of adult disease' hypothesis (Lane 2014). Animal studies from both rodents (Samuelsson et al. 2008, Nivoit et al. 2009, Song et al. 2012, Mouralidarane et al. 2013, Elshenawy \& Simmons 2016) and nonhuman primates (McCurdy et al. 2009) supported the fact that maternal high-fat diet (HFD) intake or hyperglycemia during pregnancy increases the rates of metabolic disorders in offspring. Detrimental impacts of maternal obesity or diabetes during perinatal periods on adiposity and metabolic function in offspring are well established, whereas the contribution of obese or diabetic fathers to these processes is poorly described. In 2010, Ng and coworkers pioneered the role of paternal obesity on the health of offspring and found that when rat fathers were fed a high-fat diet, the resulting female offspring exhibited impaired glucose tolerance and insulin secretion as young adults ( $\mathrm{Ng}$ et al. 2010). Later on, a variety of studies showed that either paternal obesity or mild diabetes can significantly alter metabolic outcomes of offspring, making them more prone to obesity, diabetes and fatty liver diseases (Fullston et al. 2013, Wei et al. 2014, Cropley et al. 2016). Evidence from human studies also suggested that in the context of parent-offspring, the magnitudes of the maternal or paternal influences on offspring phenotype are almost identical (Kivimäki et al. 2007, Soubry et al. 2013, Wells 2014). Although strong associations between adult disease risk and environmental perturbations experienced during early development have been identified, the impact of paternal metabolic status around conception remains poorly understood. Obese male may associate with reduced pregnancy rates due to the impairment in sperm motility, increased sperm abnormality and decreased blastocyst developmental rates (Ghanayem et al. 2010). In addition, in response to paternal HFD (Mitchell et al. 2011), low protein diet feeding (Carone et al. 2010) or preconceptional fasting (Anderson et al. 2006), metabolic profiles of offspring are significantly altered including hepatic lipid metabolism and pancreatic $\beta$-cell function, which may possibly be related to changes in DNA methylation status of the imprinting genes.

The majority of studies on intergenerational transmission of metabolic disorders are from rodent models of diet-induced obesity, which include a variety of metabolic abnormalities such as hyperglycemia, hyperleptinemia, dyslipidemia and metabolic inflammation. Thus, it is difficult to distinguish the role of each metabolic index in mediating transgenerational inheritance of metabolic dysfunction. To address this issue, we produced a relatively pure hyperglycemic rat model by single injection of low-dose streptozocin (STZ) (Deeds et al. 2011), and then bred with healthy female rats to generate offspring from STZ fathers (STZ-O), in comparison with those from citrate buffer (CB)-treated euglycemic fathers (CB-O). Our aim was to determine the impact of a paternal hyperglycemia on metabolic homeostasis of adult offspring, with particular focus on analysis of changes in hypothalamus-mediated food intake and energy expenditure.

\section{Materials and methods}

\section{Animals}

All experimental procedures were approved by the Animal Ethics Committee, the First Affiliated Hospital of Chongqing Medical University (Approval number: 2014-2017). Male and female Sprague-Dawley (SD) rats were purchased from Chongqing Medical University Laboratory Animal Centre (Chongqing, China) and housed under a $12 \mathrm{~h} / 12 \mathrm{~h}$ light/darkness cycle with lights on from 07:00 to 19:00 humidity-controlled rooms at $22^{\circ} \mathrm{C}$. The male rats randomly received two different treatments: streptozocin (STZ, S0130, Sigma) and CB. After one-week acclimatization, hyperglycemic model was induced by intraperitoneal injection of STZ $(35 \mathrm{mg} / \mathrm{kg}$ body weight) dissolved in $0.1 \mathrm{M} \mathrm{CB}, \mathrm{pH} 4.3$, and control rats received an equal volume of $\mathrm{CB}$ after $16 \mathrm{~h}$ of fasting. Glucose levels were measured by using a glucose analyzer (Roche Instruments), and rats with glucose levels were persistently higher than $16.7 \mathrm{mM}$ at the 3rd, 6th and 9th day after STZ injection and immediately before mating (45th day after STZ treatment) were considered as hyperglycemia and used for subsequent experiments. Rats satisfied with these hyperglycemic criteria after STZ injection (STZ, $n=15)$ and control CB-treated rats (CB, $n=10$ ) were mated with age-matched healthy female rats. The males were removed from the cages immediately when the females were confirmed pregnancy. The offspring were labeled according to their fathers, forming two groups: STZ-O (STZ-offspring) and CB-O (CB-offspring).

Published by Bioscientifica Ltd. 
Subsequently, the litter size was adjusted to eight pups per dam at postpartum day 2. After weaning (postpartum 21 days), all pups were housed by sex. The rats were weighed every week. All animals were maintained on a rodent regular chow diet (Composition: fat $4.5 \%$, protein $20 \%$ and carbohydrate 57\%; Energy contents: fat $11.6 \%$, protein $23 \%$ and carbohydrate $65.4 \%$ ) and had free access to water throughout the study (Fig. 1A). At the end of the experiment, animals were killed by $\mathrm{CO}_{2}$ inhalation under the non-fasting condition except for some specific fasting/ refeeding test was required. Body weight was monitored based on the sex from all offspring. For the measurement of other metabolic parameters, one male rat from each litter was randomly selected.

\section{Food intake and cold challenge}

Measurement of food intake and acute cold challenge test were performed in the individually caged rats. Fastingrefeeding test was implemented in young (6 weeks) and adult (20 weeks) male offspring. Food intake was measured at a 12-h fasting followed by a 12-h refeeding period. In addition, the daily food consumption of three consecutive weeks (24-26 weeks) ad libitum was also monitored every day. Subsequently, cold exposure $\left(4^{\circ} \mathrm{C}\right)$ and room temperature $\left(22^{\circ} \mathrm{C}\right)$ for $6 \mathrm{~h}$ were conducted on male STZ-O and CB-O to examine the changes in the thermogenic capacities.

\section{Glucose tolerance tests (GTTs) and insulin tolerance tests (ITTs)}

GTTs were performed at 12, 22 and 32 weeks of age, and ITTs were performed at 30 weeks as our previous reports (Song et al. 2012, Wang et al. 2015). Briefly, rats were fasted for $16 \mathrm{~h}$, and GTTs were performed as follows: after collecting blood from the tail (0 time), the rats received glucose $(2 \mathrm{~g} / \mathrm{kg}$ body weight) via intraperitoneal injection and blood glucose was measured at 15, 30, 60 and $120 \mathrm{~min}$ points. ITTs were performed $4 \mathrm{~h}$ after fasting, and
A
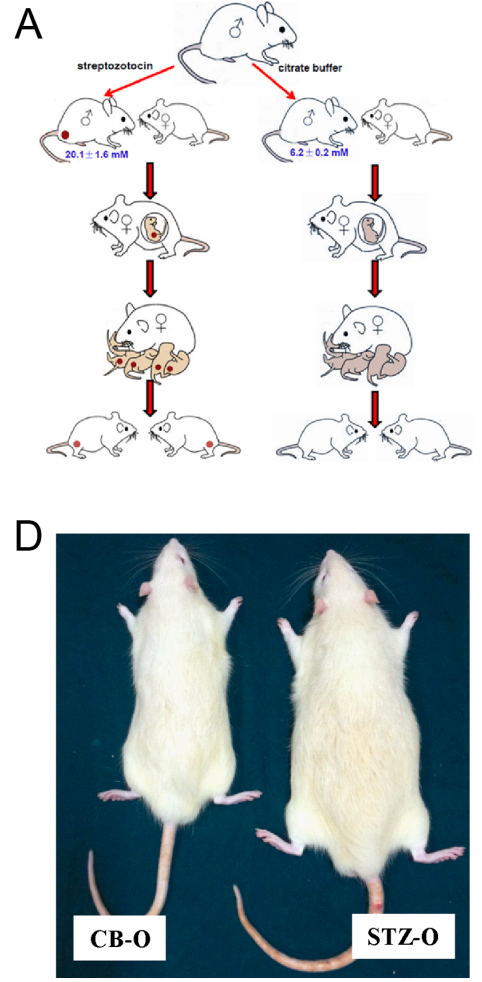

B

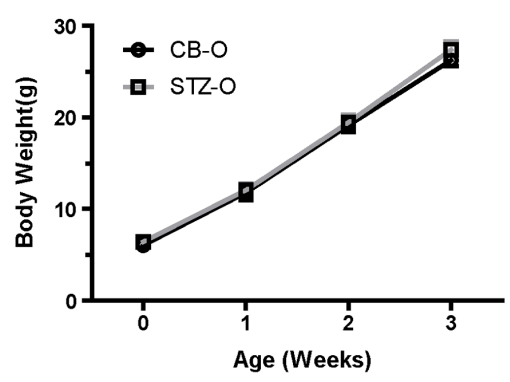

E

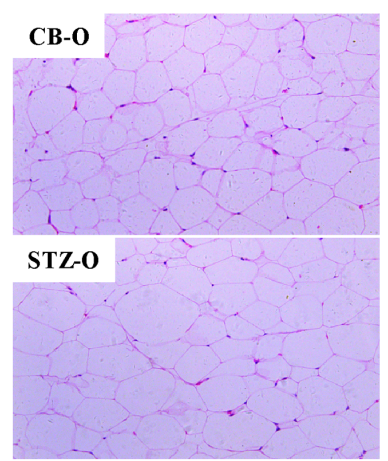

$\mathrm{F}$
C
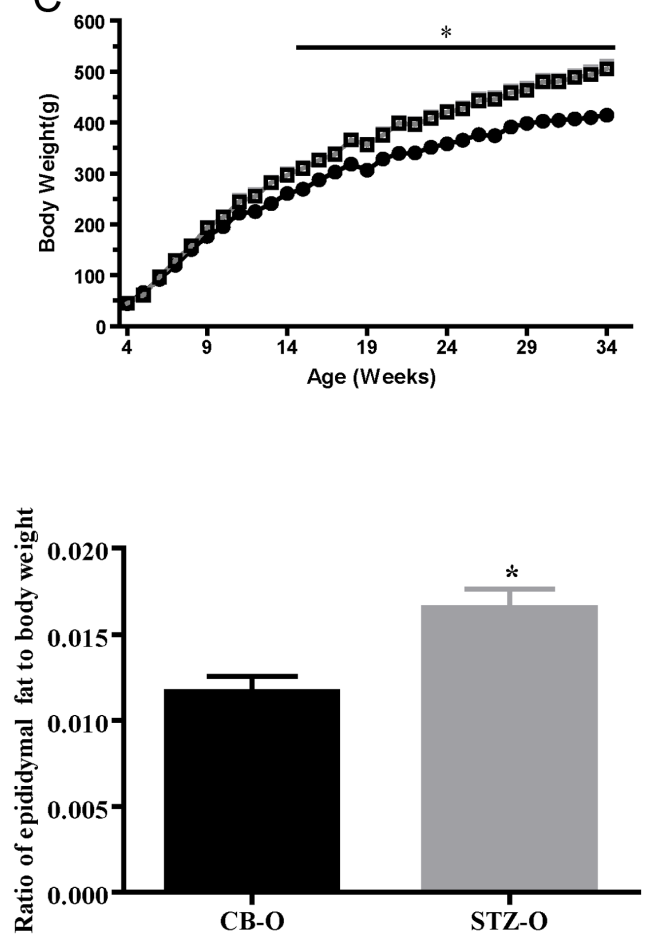

Figure 1

Paternal hyperglycemia induced significant weight gain and obesity in offspring. (A) Study design; (B) body weight of STZ-O and CB-O during lactation (STZ-O: $n=118$ from 15 different litters; CB-O: $n=78$ from 10 different litters); (C) body weight of male STZ-O and CB-O after weaning (STZ-O: $n=68$; CB-O, $n=44)$; (D) body size of male offspring at 20 weeks of age; (E) representative H\&E staining of WAT from male CB-O and STZ-O; (F) epididymal WAT mass standardized to body weight of male offspring ( $n=9$ for each group). The data are expressed as mean \pm S.E.M., and the differences between the two groups were analyzed with Student's $t$-test, $* P<0.05$.

http://joe.endocrinology-journals.org DOI: 10.1530/JOE-17-0082
๑) 2017 Society for Endocrinology Printed in Great Britain
Published by Bioscientifica Ltd. 
human recombinant insulin (1 unit/kg, Actrapid, Novo Nordisk) was intraperitoneally injected and blood glucose was measured at 0, 30, 60, 90 and $120 \mathrm{~min}$. For GTTs and ITTs, the data were plotted as blood glucose concentration over time.

\section{Adipose tissue histological and immunohistochemistry analysis}

Epididymal white adipose tissue (WAT) and interscapular brown adipose tissue (BAT) were carefully isolated, and then fixed in $4 \%$ paraformaldehyde at $4^{\circ} \mathrm{C}$, embedded in paraffin, serially sectioned, stained with hematoxylineosin (H\&E) for the assessment of cell morphology study. UCP1 (ab23841) immunohistochemistry was performed in BAT according to the manufacturer's instructions (Chengdu Biological Technology Co., Ltd). The UCP1 positive cells were quantified by Image $\mathrm{J}$ software, and expressed as the percentage of UCP1-positive area to the total area.

\section{Plasma leptin and $\alpha-M S H$ assay}

The plasma was separated by centrifugation $(3000 \boldsymbol{g}$ for $15 \mathrm{~min})$ at $4^{\circ} \mathrm{C}$ and stored at $-80^{\circ} \mathrm{C}$ until the biochemical tests were performed. The plasma leptin and $\alpha$-melanocyte stimulating hormone $(\alpha-\mathrm{MSH})$ concentrations were measured in duplicate using immunoenzymatic test kits (Rat leptin ELISA kit, CK-E30492R and rat $\alpha$-MSH ELISA Kit, CK-E94745R, BIOSAMITE).

\section{RNA isolation and quantitative RT-PCR analysis}

Total RNA of the hypothalamus and BAT was extracted with TRlzol (Invitrogen), and the RNA quantity was measured using Nanodrop 2000 system (Thermo Scientific). cDNA was synthesized according to the manufacturer's instructions of the Reverse Transcription Kit (TaKaRa). Quantitative real-time PCR was performed in a $10 \mu \mathrm{L}$ final reaction volume with SYBR Green (Roche) on a C1000 Thermal Cycler CFX96 Real-Time System (BioRad) in triplicates. Amplification was carried out at $95^{\circ} \mathrm{C}$ for $4 \mathrm{~s}, 60^{\circ} \mathrm{C}$ for $10 \mathrm{~s}$ and $65^{\circ} \mathrm{C}$ for $5 \mathrm{~s}$. This was repeated for 40 cycles. The mRNA expression levels were calculated using the formula $2^{-\Delta \Delta \mathrm{Ct}}$ (where $\Delta \Delta \mathrm{Ct}=\Delta \mathrm{Ct}$ sample $-\Delta$ Ct reference). The primers used were listed in Table 1.
Table 1 Sequences of the primer pairs used in the RT-PCR.

\begin{tabular}{|c|c|c|}
\hline \multirow{2}{*}{$\begin{array}{l}\text { Gene } \\
\beta \text {-Actin }\end{array}$} & \multicolumn{2}{|c|}{ Primers $\left(5^{\prime} \rightarrow 3^{\prime}\right)$} \\
\hline & Forward & TCACCAACTGGGACGATA \\
\hline & Reverse & AGGCATACAGGGACAACA \\
\hline \multirow[t]{2}{*}{ LepR } & Forward & TCACCCAGCACAATCCAATCA \\
\hline & Reverse & GCCATCTGTCTGTAAGACGCAGT \\
\hline \multirow[t]{2}{*}{ SOCS3 } & Forward & CCAGTCGGGGACCAAGAACC \\
\hline & Reverse & TGAGTACACAGTCAAAGCGGGG \\
\hline \multirow[t]{2}{*}{ NPY } & Forward & CTGCGACACTACATCAATCT \\
\hline & Reverse & ATACAACGACAACAAGGGA \\
\hline \multirow[t]{2}{*}{ POMC } & Forward & GATGCCGAGATTCTGCTACA \\
\hline & Reverse & TGCTTTCCGTGGTGAGGT \\
\hline \multirow[t]{2}{*}{$P C 1$} & Forward & TCACCCTCTTTTTGCGTTTGG \\
\hline & Reverse & TCTCCGCCGCCCATT \\
\hline \multirow[t]{2}{*}{$P C 2$} & Forward & AAGACGGAGAGGAAGAGG \\
\hline & Reverse & GCATCAGAGTTATAGTTGTAGG \\
\hline \multirow[t]{2}{*}{$C P E$} & Forward & TGGTAATGAGGCGGTTGGAC \\
\hline & Reverse & TCAAGGAGGGCATGATATGGAT \\
\hline \multirow[t]{2}{*}{ Ucp1 } & Forward & TGGCGTGGCGGTATTCA \\
\hline & Reverse & GGCTTTGTGCTTGCATTCTG \\
\hline
\end{tabular}

\section{Protein extraction and Western blot analysis}

Total protein was extracted from frozen hypothalamus using RIPA buffer (Thermo Scientific) containing protease and phosphatase inhibitors (Roche). The ultrasonic fragmentation was centrifuged $(14,000 \boldsymbol{g}$ for $15 \mathrm{~min})$ at $4^{\circ} \mathrm{C}$, and the supernatant was collected. Subsequently, the protein concentration was determined with the BCA kit (Beyotime). Fifty microgram protein was loaded onto $10 \%$ SDS-PAGE, transferred to $0.45 \mu \mathrm{m}$ PVDF membranes and then blocked with $5 \%$ bovine serum (BSA) at room temperature for $2 \mathrm{~h}$ to prevent nonspecific binding. The membrane was incubated overnight at $4^{\circ} \mathrm{C}$ with following primary antibodies: p-STAT3 $(1: 1000,9145$, Tyr705) and STAT3 (1:1000, 9139) (Cell Signaling Technology), and suppressor of cytokine signaling 3 (SOCS3) (1:1000, ab16030), and then the secondary antibodies for $1 \mathrm{~h}$ at room temperature. The protein bands were visualized with enhanced chemiluminescence (ECL) detection system. The band intensity was quantified with Fusion software, and all quantitative analyses were normalized to $\beta$-actin.

\section{Statistical analysis}

Statistical differences were analyzed by two-tailed Student's $t$-test or one-way ANOVA using GraphPad prism analysis software. All experimental data were represented as the mean \pm S.E.M. $P<0.05$ was considered statistically significant. 


\section{Results}

\section{Paternal hyperglycemia resulted in significant weight} gain and obesity in offspring

Among 25 rats that received single injection of $35 \mathrm{mg} / \mathrm{kg}$ of STZ, 15 rats (60\%) met our hyperglycemic criteria: glucose levels persistently higher than $16.7 \mathrm{mM}$ at the 3rd, 6th, 9th and 45th day after STZ injection. In these rats, STZ triggered a 3-fold increase in blood glucose levels (data not shown). No obvious changes were observed in the structure of the testis and epididymis in these male hyperglycemic rats (data not shown). Body weight of the offspring born from STZ and CB treated fathers (STZ-O and $\mathrm{CB}-\mathrm{O}$ ) did not differ at birth, during lactation and young adults (Fig. 1B and C). However, beginning with 14 weeks of age, STZ-O gained more weight than their CB-O counterparts (Fig. 1C). In addition, STZ-O also had larger body size (Fig. 1D). White adipose tissue (WAT) H\&E staining indicated the presence of extensive adipocyte expansion with increased adipocyte size in STZ-O (Fig. 1E), in correspondence with increased fat mass in STZ-O (Fig. 1F).

\section{Paternal hyperglycemia induced glucose intolerance and reduced insulin sensitivity in male offspring}

To test whether paternal hyperglycemia altered glucose homeostasis and insulin sensitivity in the offspring,
GTTs (Fig. 2A, B and C) and ITTs (Fig. 2D) were performed at the different ages of STZ-O and CB-O. At the ages of 12 and 22 weeks (Fig. $2 \mathrm{~A}$ and B), no significant changes were observed between STZ-O and CB-O in GTTs. However, at the age of 32 weeks (Fig. 2C), significantly higher glucose levels were observed in STZ-O rats at 15 min after glucose loading, suggesting glucose intolerance in STZ-O compared with CB-O. In addition, the hypoglycemic effects after insulin treatment were significantly attenuated in STZ-O rats at 30 weeks of ages (Fig. 2D), suggesting reduced insulin sensitivity.

\section{The offspring of hyperglycemic fathers exhibited hyperphagia}

To examine whether more weight gain and adiposity of offspring from paternal hyperglycemia resulted from higher food consumption, we evaluated their ability to adapt energy intake by measuring the amount of refed food at 1, 2, 6 and $12 \mathrm{~h}$ after an overnight fast. As shown in Fig. 3A, at 6 weeks of age, male STZ-O exhibited significantly higher food consumption within $12 \mathrm{~h}$ after an overnight fast, and higher food intake within $12 \mathrm{~h}$ after an overnight fast was observed in the male STZ-O at 20 weeks of age (Fig. 3B). In addition, we examined daily food intake at ad libitum feeding conditions. Remarkably, male STZ-O showed hyperphagia compared to CB-O at 26 weeks of age (Fig. 3C).
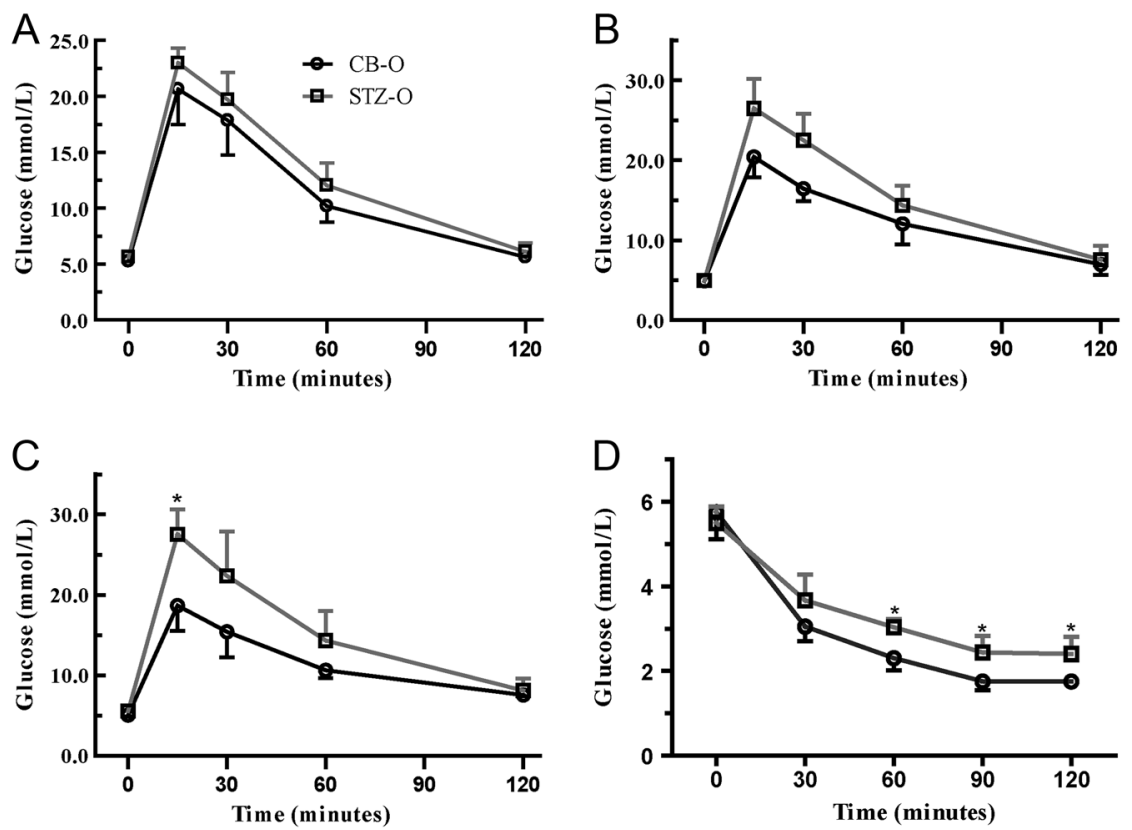

Figure 2

Paternal hyperglycemia induced glucose intolerance and reduced insulin sensitivity in male offspring. Glucose tolerance tests (GTTs) were performed at 12 (A), 22 (B), and 32 weeks of age (C). Insulin tolerance tests (ITTs) were performed at the age of 30 weeks (D). The data are expressed as mean \pm S.E.M., $n=6-8$ for each group and test, and the differences between the two groups at the same time point were analyzed with Student's $t$-test, ${ }^{*} P<0.05$. 
A

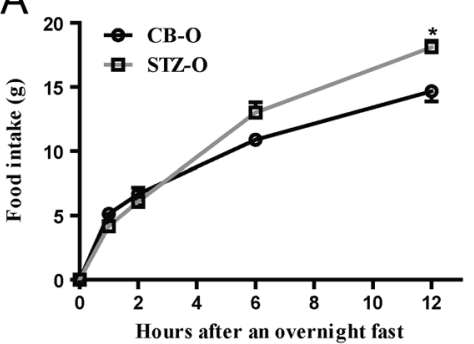

$\mathrm{B}$

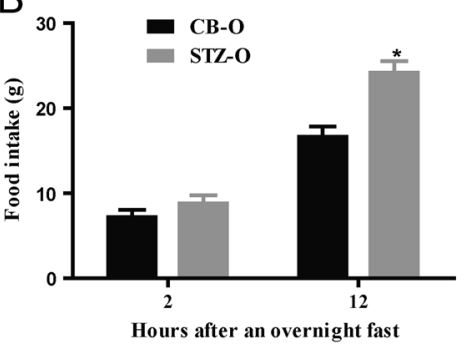

C

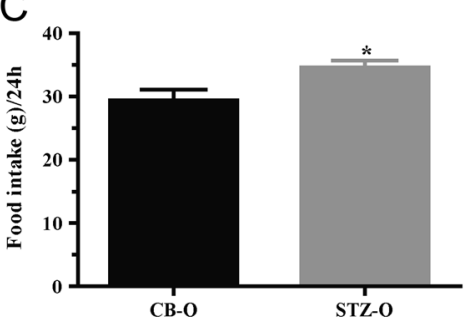

Figure 3

The offspring of hyperglycemic fathers exhibited hyperphagia. Food intake at 1-, 2-, 6- and 12-h after an overnight fast in male offspring at 6 week of age (A); food intake at 2- and 12-h after an overnight fast of male offspring at 20 weeks of age (B); average daily food intake of male offspring at 26 weeks of age (C). Values are expressed as mean \pm S.E.M., $n=8$ for each group, and the differences between the two groups were analyzed with Student's t-test, $* P<0.05$

\section{Paternal hyperglycemia impaired BAT thermogenic capacity in male offspring}

To test whether energy expenditure is involved in paternal hyperglycemia-induced obesity in offspring, we examined BAT histological changes and expression of thermogenic gene UCP1 in STZ-O and CB-O. Figure 4A and $\mathrm{B}$ shows histological changes in STZ-O and CB-O rats maintained at $21-22^{\circ} \mathrm{C}(\mathrm{RT})$. Brown adipocytes from CB-O rats exhibited typically multilocular, with the bulk of the cell being occupied by numerous circular lipid droplets with various sizes, whereas in STZ-O BAT, larger and more circular lipid droplets were obvious, similar to the histological characteristics of WATs. Impaired thermogenic capacities in STZ-O rats were further confirmed by UCP1 expression. There were plentiful UCP1 positive cells in BAT from CB-O rats at room temperature (Fig. 4C and E). Compared with CB-O, only fewer UCP1 positive cells were observed in BAT from STZ-O rats (Fig. 4D and E). Acute exposure of normal animals to $4^{\circ} \mathrm{C}$ (cold exposure) is a well-established method investigating functional activity of BAT-mediated nonshivering thermogenesis. Both basal and cold-induced Ucp1 mRNA
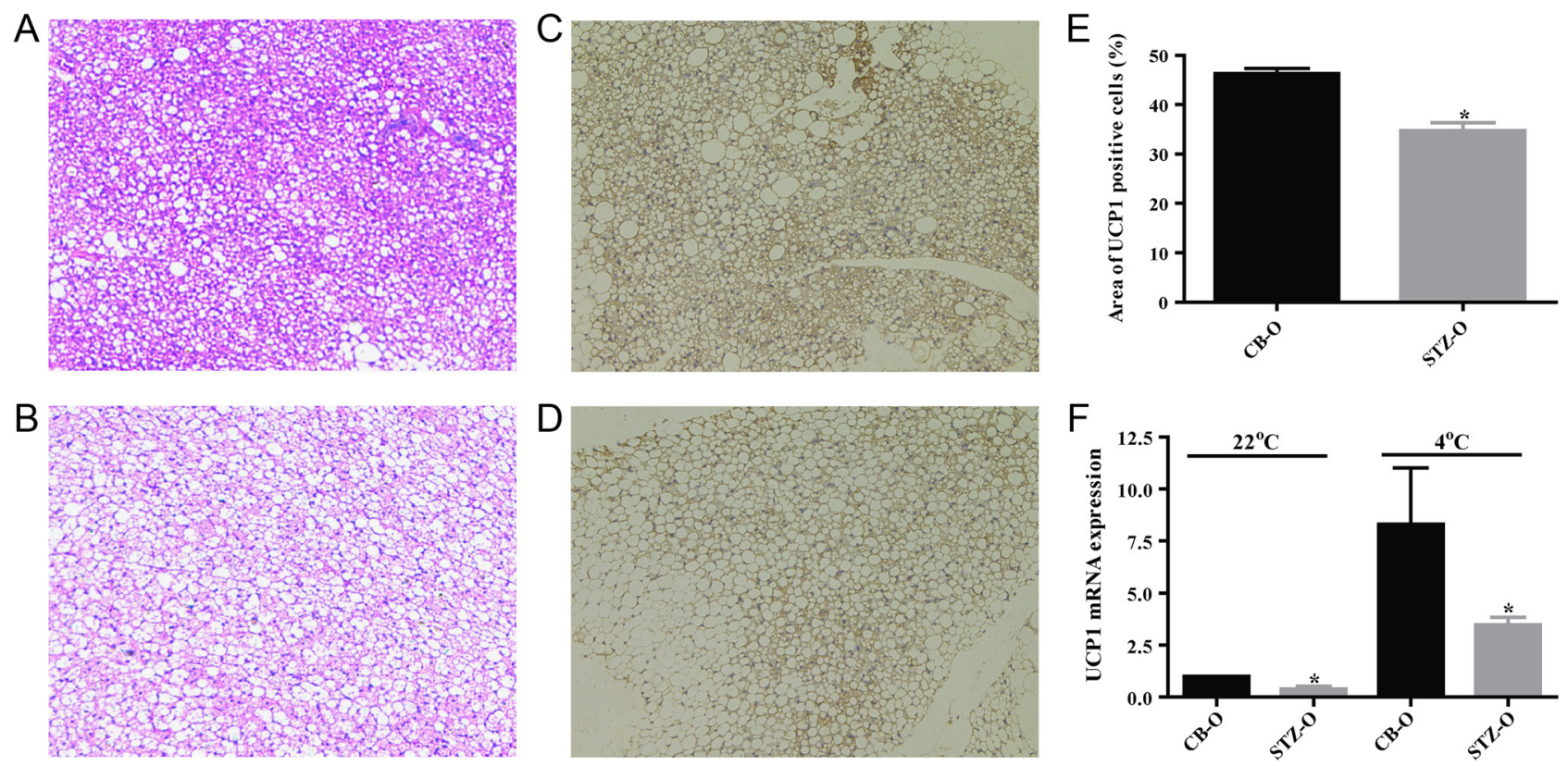

Figure 4

Paternal hyperglycemia impaired BAT thermogenic capacity in male offspring. Representative H\&E staining of BAT from CB-O (A) and STZ-O (B); representative UCP1 immunohistochemistry of BAT from CB-O (C) and STZ-O (D); quantified UCP1 positive cells in CB-O and STZ-O (E); relative expression of Ucp 1 mRNA in BAT from CB-O and STZ-O at room temperature $\left(22^{\circ} \mathrm{C}\right)$ and cold conditions $\left(4^{\circ} \mathrm{C}\right)(\mathrm{F})$. The data are expressed as mean \pm S.E.M., $n=8$ for each group and treatment, and the differences between the two groups were analyzed with Student's $t$-test, ${ }^{*} P<0.05$.

http://joe.endocrinology-journals.org DOI: 10.1530/JOE-17-0082
๑) 2017 Society for Endocrinology Printed in Great Britain
Published by Bioscientifica Ltd 
expression showed a remarkable reduction in BAT from STZ-O in comparison with those from CB-O rats (Fig. 4F), indicating a reduced BAT nonshivering thermogenesis in STZ-O animals.

\section{Paternal hyperglycemia affected hypothalamic $\alpha$-MSH processing and circulating $\alpha$-MSH levels in male offspring}

Proopiomelanocortin (POMC)-containing neurons represent the master subset of hypothalamic anorexigenic neurons, being the source of the $\alpha$-melanocytestimulating hormone ( $\alpha$-MSH), which suppresses feeding and/or stimulates energy expenditure. As shown in Fig. 5A, under conditions of fasting, serum $\alpha-\mathrm{MSH}$ levels of STZ-O rats were lower than CB-O, and lower $\alpha$-MSH levels of STZ-O rats were maintained at 2 and $12 \mathrm{~h}$ after refeeding. $\alpha$-MSH was produced from POMC through a series of enzymatic cleavage including type
1 and type 2 prohormone convertase (PC1 and PC2) and carboxypeptidase E (CPE) (Nillni 2016) (Fig. 5B). To test if changes in POMC expression and processing contribute to reduction of $\alpha-\mathrm{MSH}$ in STZ-O rats, we detected hypothalamic mRNA levels of Pomc and $\alpha$-MSH-producing enzymes. As shown in Fig. 5C, D, E and F, hypothalamic mRNA levels of Pomc and Pc1, Pc2 and Cpe were consistently downregulated in STZ-O rats, suggesting downregulated POMC expressing and impairment in $\alpha$-MSH-processing contribute to the lower levels of $\alpha$-MSH in STZ-O rats.

\section{Paternal hyperglycemia affected hypothalamic leptin signaling in male offspring}

Leptin signaling plays crucial role in the control of food intake and energy expenditure in response to an altered energy state (Kwon et al. 2016). To investigate whether paternal hyperglycemia had effect on central leptin
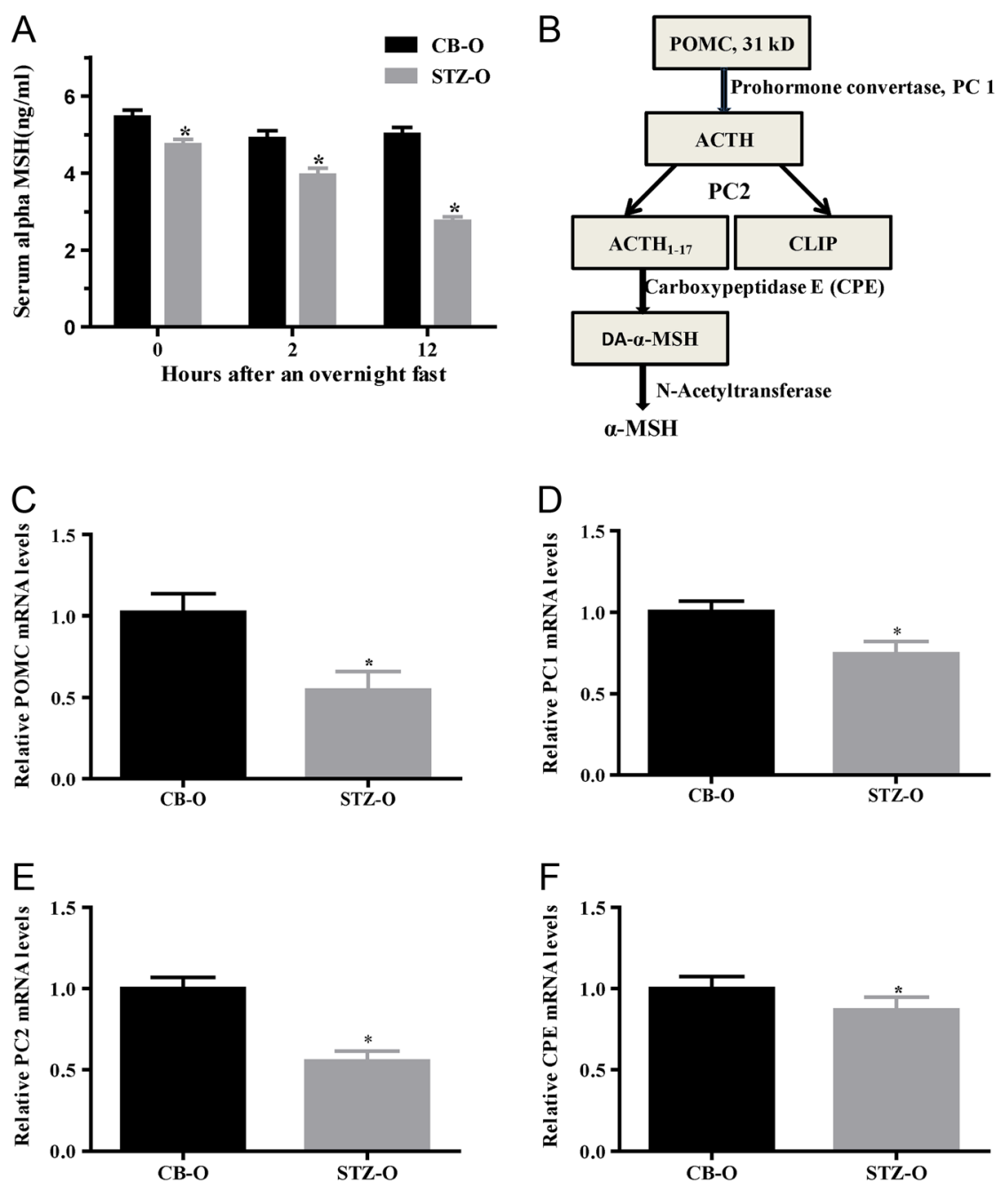
Figure 5
Paternal hyperglycemia affected hypothalamic POMC processing and circulating $\alpha-M S H$ levels in male offspring. (A) Serum $\alpha$-MSH levels; (B) schematic representation of POMC cleavage and $\alpha$-MSH production; transcriptional levels of prohormone convertase (PC1, C) and PC2 (D), and carboxypeptidase $\mathrm{E}(\mathrm{CPE}, \mathrm{E})$. The data were expressed as mean \pm S.E.M., $n=8$ for each group, and the differences between the two groups were analyzed with Student's $t$-test, $* P<0.05$.



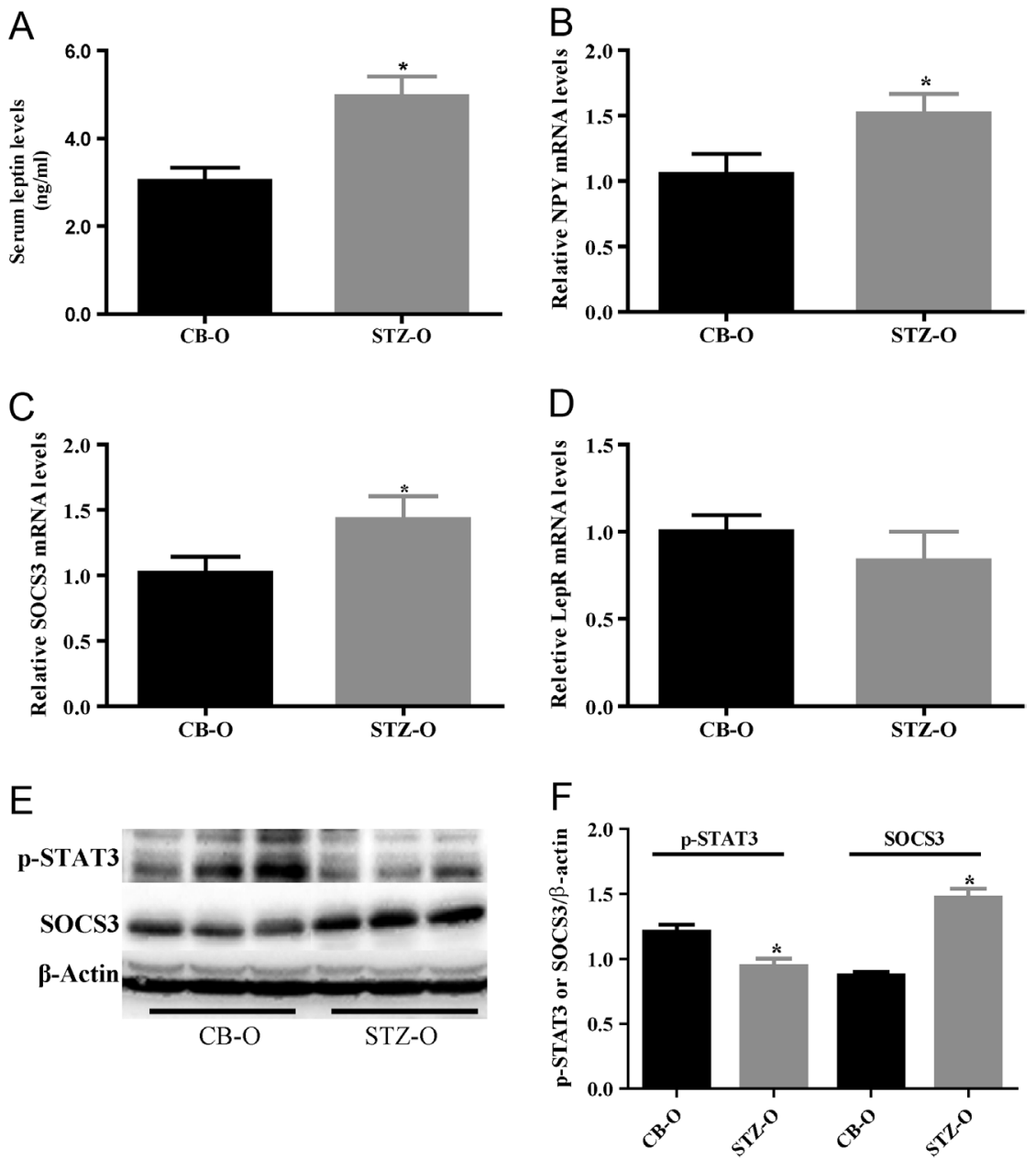

\begin{abstract}
Figure 6
Paternal hyperglycemia affected hypothalamic leptin signaling in male offspring (A) Serum leptin levels; hypothalamic mRNA levels of

neuropeptide $Y(N p y, B)$, suppressor of cytokine signaling 3 (Socs3, C) and leptin receptor (LepR, D); (E) Western blot analysis of phosphorylated signal transducer and activator of transcription 3 ( $p$-STAT3) and SOCS3 protein levels in hypothalamic extracts. (F) Quantified p-STAT3 and SOCS3 protein levels. The data were expressed as mean \pm S.E.M., $n=6-8$ for each group, and the differences between the two groups were analyzed with Student's $t$-test, $* P<0.05$.
\end{abstract}

signaling, the key components of the JAK/STAT signaling pathways were examined in the hypothalamus. STZ-O rats exhibited hyperleptinemia (Fig. 6A), but without inhibitory effect on food intake (Fig. 4), suggesting a typical leptin resistance. Neuropeptide Y (NPY) is the most important orexigenic peptide, which was significantly upregulated in the hypothalamus of STZ-O rats (Fig. 6B). Suppressor of cytokine signaling 3 (SOCS3) is an inhibitory protein of the leptin signaling pathway. In this study, hypothalamic Socs3 mRNA (Fig. 6C) and protein levels (Fig. 6E and F) were higher in STZ-O rats, while LepR mRNA levels (Fig. 6D) did not differ. Phosphorylated signaling transducers and activators of transcription 3 (p-STAT3) is the key hallmarker of leptin signaling activation. Compared with CB-O, p-STAT3 was decreased in STZ-O rats (Fig. 6E and F), suggesting the impaired leptin signaling in STZ-O rats. These findings indicate that paternal hyperglycemia leads to leptin resistance in the offspring.

\section{Discussion}

Our present study revealed that compared to the euglycemic fathers, paternal hyperglycemia could induce more weight gain in the offspring, and offspring from hyperglycemic fathers displayed hyperphagia and impaired BAT thermogenesis, which may possibly contribute to their increased adiposity. Excess energy intake and obesity altered multiple metabolic organs and resulted in reduced insulin sensitivity and impaired glucose tolerance. Furthermore, these offspring displayed significant defects in hypothalamic leptin signaling, evidenced by reduction of anorexigenic peptide $\alpha$-MSH levels and hypothalamic mRNA levels of its precursors (POMC) and processing enzymes (PC1, PC2 and CPE), increased expression of orexigenic NPY and decreased phosphorylation of STAT3. Hence, these findings strongly indicated that paternal hyperglycemia has a long-term impact on the regulation of energy homeostasis and 
increases the risk of developing metabolic diseases in their next generation.

The transgenerational inheritance of acquired metabolic disorders may contribute to recent obesity and diabetes pandemic. Typically, the majority of studies as to whether and how early-life events influence later susceptibility to metabolic diseases, including ours, are from mothers (Song et al. 2012, Wang et al. 2015, Damm et al. 2016, Godfrey et al. 2016). Although maternal nutrition and metabolic status during gestation and lactation are undeniably linked to health of offspring, recent studies have shown that paternal environmental, nutritional or behavioral factors affect the phenotype of the offspring as well ( $\mathrm{Ng}$ et al. 2010, Fullston et al. 2013, Braun \& Champagne 2014, Wei et al. 2014, Cropley et al. 2016, Wu et al. 2016). In this study, offspring from paternal hyperglycemia were born normal and maintained normal body weight as young adult under standard diets. These data were generally consistent with the results of paternal obese (Cropley et al. 2016, Masuyama et al. 2016) or prediabetes (Wei et al. 2014) models. In comparison with Wei's findings, which utilized paternal obesity plus minor hyperglycemia (fasting blood glucose levels were at 7-11 mM, prediabetes) model and body weight of offspring was observed at relatively young age (16 week), our study uniquely revealed that severe paternal hyperglycemia per se significantly altered metabolic characters and induced a late onset weight gain in offspring. At birth and early developmental stages, the normal body weight of offspring born from diabetic fathers was possibly attributable to the protective mechanisms against an inadequate metabolic environment such as excess of metabolites and hormones. After adolescents, offspring from diabetic fathers gained more weight and adiposity overtaking their control counterparts, in agreeing with the results observed from paternal obesity (Masuyama et al. 2016). In addition to adiposity, paternal hyperglycemia was found to be linked to other metabolic abnormalities in offspring, including glucose intolerance, reduced insulin sensitivity, dyslipidemia and hyperleptinemia, which were observed in the offspring of paternal obesity ( $\mathrm{Ng}$ et al. 2010, Fullston et al. 2013, 2015, Ornellas et al. 2015). The obesity is a very complicated condition, confounded with a broad spectrum of metabolic abnormalities, including adiposity, metabolic inflammation, glucose intolerance, $\beta$-cell dysfunction and altered secretion of hormones and cytokines (Gregor \& Hotamisligil 2011, Dali-Youcef et al. 2013). Therefore, it is hard to distinguish which individual factor contributes to metabolic programming in the model paternal obesity. In our study, a single low dose of STZ was used, which has been widely used to induce experimental diabetes and diabetic complications in rodents (Tesch \& Allen 2007, Lenzen 2008, Song et al. 2012). The most important mechanism of streptozotocin-induced diabetes is pancreatic $\beta$-cell death due to DNA alkylation. In addition, generation of reactive oxygen/nitrogen species (ROS/RNS) also contributes to streptozotocin toxic effect on $\beta$ cells and diabetogenic effect (Elsner et al. 2000, Lenzen 2008). STZ has a short life due to the quick metabolizing and elimination and its half-life time is about $15 \mathrm{~min}$ in the serum after intravenous injection (Eleazu et al. 2013). Based on its short life time, the acute toxicity of STZ could be neglected after persistent hyperglycemia is obtained, and any further functional changes in metabolism may be attributed to the effects of diabetic hyperglycemia after STZ is eliminated out of the body. Thus, our data provide important evidence to confirm that in addition to obesity and obesity-related metabolic abnormalities, paternal hyperglycemia per se can significantly affect offspring phenotype.

STZ-O were born normal and maintained healthy body weight during youth and adolescents. Surprisingly, at 6 weeks of age, STZ-O were evident in higher food intake but maintained normal body weight as their CB-O counterparts, which may possibly be attributable to diet-induced thermogenesis and an activation of brown fat, where UCP1 could serve to burn off excess calories to maintain energy balance, thus opposing weight gain (Westerterp 2013). However, STZ-O gained more weight and adiposity after young adults, and this has been observed in other rodent (Berends et al. 2013) and nonhuman primate (Sullivan et al. 2017) metabolic programming models. The body weight change between STZ-O and CB-O may be possibly through metabolic regulation of the hypothalamic feeding circuits, which could further alter food intake and energy expenditure (Gao \& Sun 2016, Lage et al. 2016). Leptin activates anorexigenic neurons and inhibits orexigenic neurons in the hypothalamus via Janus tyrosine kinase 2 (JAK2) and signal transducer and activator of transcription 3 (STAT3)-mediated pathways, resulting in reduced food intake and increased energy expenditure (Williams \& Schwartz 2011, Roh et al. 2016) A hallmark of obesity is leptin resistance, in which highcirculating leptin levels are unable to promote its central anorexigenic effects. As abundant food availability and feeding behavior play an important role in the obesity epidemic (Ellacott et al. 2010), we thus performed fastrefeed test and measured daily food intake in adult STZ-O
Published by Bioscientifica Ltd 
and $\mathrm{CB}-\mathrm{O}$ as young and adults under standard chow diets. Food deprivation generally results in a reduction in plasma concentration of leptin, and low plasma leptin levels trigger a series of adaptive neuroendocrine responses to increase food intake, and amount of the consumed food after refeeding is an ideal indicator as appetite (Ahima 2000). At 6 weeks of age, male STZ-O exhibited higher appetite as reflected by higher food consumed within $12 \mathrm{~h}$ after an overnight fast, while female STZ-O did not differ, suggesting there is a potential sex-specific feeding pattern in rats (Zandian et al. 2011, Fukushima et al. 2015). Sexual differences of offspring in response to changes in paternal glycemia may be attributable to the activational role of sex hormones at puberty in male and females, as rise in estrogen acts as a reducing factor of feeding (Xu et al. 2011, Fukushima et al. 2015). Of note, no obvious changes in body weight were observed between STZ-O and CB-O at this age. We speculate that in response to higher intake of caloric energy, a metabolic adaptation was triggered in young STZ-O animals as an attempt to control weight gain, possibly by consuming the excess energy through increased thermogenesis. Higher food intake within $12 \mathrm{~h}$ after an overnight fast and daily food intake was observed after 20 weeks of age in STZ-O, in consistence with increased weight gain and adiposity. BAT is a specialized fat depot that can increase energy expenditure through non-shivering thermogenesis (Sidossis \& Kajimura 2015, Kalinovich et al. 2017). Changes in histological features and Ucp1 mRNA and protein levels suggested that brown fat from adult STZ-O was less active compared with CB-O at neutral temperature. In addition, cold-induced $U c p 1$ mRNA expression was significantly reduced in adult STZ-O rats. All these data implied that both increased food intake and impaired energy expenditure contribute to the phenotype of adult STZ-O rats.

Excess weight gain and obesity result from an imbalance between energy intake and energy expenditure. Hypothalamic leptin signaling plays a crucial role in the control of food intake and energy expenditure (Caron \& Richard 2016, Kwon et al. 2016, Roh et al. 2016). In this study, STAT3 phosphorylation (pSTAT3), a key component of leptin signaling, was detected by immunoblotting tests in the hypothalamus from both STZ-O and CB-O. Compared with CB-O, pSTAT3 proteins were significantly reduced in STZ-O, suggesting significant hypothalamic leptin resistance. Physiologically, the activation of leptin signaling may further modulate the action of a series of neuropeptides, mainly inhibiting orexigenic neuropeptide
Y (NPY) and promoting anorectic proopiomelanocortin (POMC) in the hypothalamus (Kageyama et al. 2012). NPY stimulates food intake, and the POMC product $\alpha$-MSH inhibits food intake (Shi et al. 2013, Loh et al. 2015). In our study, STZ-O showed a significantly high hypothalamic NPY expression, reduced mRNA levels of Pomc and $\alpha-\mathrm{MSH}$-processing enzymes, and more importantly, lowcirculating $\alpha$-MSH concentrations.

Due to the technical difficulty, we are unable to detect the levels of $\alpha$-MSH in cerebrospinal fluid (CSF) or hypothalamic tissues. However, peripheral serum levels of $\alpha-\mathrm{MSH}$ may well correlate with any parameter of adiposity, and a substantial amount of $\alpha-\mathrm{MSH}$ in the blood was produced by the pituitary (Gavrila et al. 2005, Enriori et al. 2016). These data could help explain leptin resistance in STZ-O rats.

In summary, our work suggests that paternal hyperglycemia programs hypothalamic feeding circuits and exacerbates the development of obesity in offspring. Our studies provide additional evidence that abnormal metabolic state of fathers can be passed to the subsequent generation; this process may be associated with hypothalamic leptin resistance. Although a clearly inherited phenotype of overweight/obesity in the second generation was observed, current study failed to address the mechanisms involved in the transgenerational inheritance through male lineage. In the future study, we will examine whether epigenetic modification is involved in transgenerational inheritance of metabolic disturbance in this specific model of paternal hyperglycemia.

\section{Declaration of interest}

The authors who have taken part in this study declared that there is no conflict of interest to disclose regarding this manuscript.

\section{Funding}

This work was supported by grants from the National Natural Science Foundation of China (81570763 and 81270947) and the National Basic Research Program of China (2012CB517505) and the Fundamental Science \& Advanced Technology Research of Chongqing (Major Project, CSTC 2015jcyjB0146) to Xiaoqiu Xiao.

\section{Author contribution statement}

$X X, X S$ and $X L$ conceptualized data collection instruments. $X X, X S, X$ $L, Q L$ and $W C$ designed data collection instruments. $X S, X L, Y H, X C, Y$ Z, H W, H W, C P and J B executed the data. X X, W C, Q L, X S, X L and J L interpreted the data. $X X, X S$ and $X L$ helped in manuscript preparation. 


\section{Acknowledgements}

The authors also thank Richa Goswami for her careful reading and editorial corrections for this manuscript.

\section{References}

Ahima RS 2000 Leptin and the neuroendocrinology of fasting. Frontiers of Hormone Research 26 42-56. (doi:10.1159/000061014)

Anderson LM, Riffle L, Wilson R, Travlos GS, Lubomirski MS \& Alvord WG 2006 Preconceptional fasting of fathers alters serum glucose in offspring of mice. Nutrition 22 327-331. (doi:10.1016/j. nut.2005.09.006)

Berends LM, Fernandez-Twinn DS, Martin-Gronert MS, Cripps RL \& Ozanne SE 2013 Catch-up growth following intra-uterine growthrestriction programmes an insulin-resistant phenotype in adipose tissue. International Journal of Obesity 37 1051-1057. (doi:10.1038/ ijo.2012.196)

Braun K \& Champagne FA 2014 Paternal influences on offspring development: behavioural and epigenetic pathways. Journal of Neuroendocrinology 26 697-706. (doi:10.1111/jne.12174)

Caron A \& Richard D 2017 Neuronal systems and circuits involved in the control of food intake and adaptive thermogenesis. Annals of the New York Academy of Sciences 1391 35-53. (doi:10.1111/nyas.13263)

Carone BR, Fauquier L, Habib N, Shea JM, Hart CE, Li R, Bock C, Li C, $\mathrm{Gu} \mathrm{H}$, Zamore PD, et al. 2010 Paternally induced transgenerational environmental reprogramming of metabolic gene expression in mammals. Cell 143 1084-1096. (doi:10.1016/j.cell.2010.12.008)

Cropley JE, Eaton SA, Aiken A, Young PE, Giannoulatou E, Ho JW, Buckland ME, Keam SP, Hutvagner G, Humphreys DT, et al. 2016 Male-lineage transmission of an acquired metabolic phenotype induced by grand-paternal obesity. Molecular Metabolism 5 699-708. (doi:10.1016/j.molmet.2016.06.008)

Dali-Youcef N, Mecili M, Ricci R \& Andrès E 2013 Metabolic inflammation: connecting obesity and insulin resistance. Annals of Medicine 45 242-253. (doi:10.3109/07853890.2012.705015)

Damm P, Houshmand-Oeregaard A, Kelstrup L, Lauenborg J, Mathiesen ER \& Clausen TD 2016 Gestational diabetes mellitus and long-term consequences for mother and offspring: a view from Denmark. Diabetologia 59 1396-1399. (doi:10.1007/s00125-016-3985-5)

Deeds MC, Anderson JM, Armstrong AS, Gastineau DA, Hiddinga HJ, Jahangir A, Eberhardt NL \& Kudva YC 2011 Single dose streptozotocin-induced diabetes: considerations for study design in islet transplantation models. Laboratory Animals 45 131-140. (doi:10.1258/la.2010.010090)

Eleazu CO, Eleazu KC, Chukwuma S \& Essien UN 2013 Review of the mechanism of cell death resulting from streptozotocin challenge in experimental animals, its practical use and potential risk to humans. Journal of Diabetes and Metabolic Disorders 12 60. (doi:10.1186/22516581-12-60)

Ellacott KLJ, Morton GJ, Woods SC, Tso P \& Schwartz MW 2010 Assessment of feeding behavior in laboratory mice. Cell Metabolism 12 10-17. (doi:10.1016/j.cmet.2010.06.001)

Elshenawy S \& Simmons R 2016 Maternal obesity and prenatal programming. Molecular and Cellular Endocrinology 435 2-6. (doi:10.1016/j.mce.2016.07.002)

Elsner M, Guldbakke B, Tiedge M, Munday R \& Lenzen S 2000 Relative importance of transport and alkylation for pancreatic beta-cell toxicity of streptozotocin. Diabetologia 43 1528-1533. (doi:10.1007/ s001250051564)

Enriori PJ, Chen W, Garcia-Rudaz MC, Grayson BE, Evans AE, Comstock SM, Gebhardt U, Müller HL, Reinehr T, Henry BA, et al. 2016 $\alpha$-Melanocyte stimulating hormone promotes muscle glucose uptake via melanocortin 5 receptors. Molecular Metabolism 5 807-822. (doi:10.1016/j.molmet.2016.07.009)

Friend A, Craig L \& Turner S 2013 The prevalence of metabolic syndrome in children: a systematic review of the literature. Metabolic Syndrome and Related Disorders 11 71-80. (doi:10.1089/met.2012.0122)

Fukushima A, Hagiwara H, Fujioka H, Kimura F, Akema T \& Funabashi T 2015 Sex differences in feeding behavior in rats: the relationship with neuronal activation in the hypothalamus. Frontiers in Neuroscience $\mathbf{9}$ 88. (doi:10.3389/fnins.2015.00088)

Fullston T, Teague EMCO, Palmer NO, DeBlasio MJ, Mitchell M, Corbett M, Print CG, Owens JA \& Lane M 2013 Paternal obesity initiates metabolic disturbances in two generations of mice with incomplete penetrance to the $\mathrm{F}-2$ generation and alters the transcriptional profile of testis and sperm microRNA content. FASEB Journal 27 4226-4243. (doi:10.1096/fj.12-224048)

Fullston T, McPherson NO, Owens JA, Kang WX, Sandeman LY \& Lane M 2015 Paternal obesity induces metabolic and sperm disturbances in male offspring that are exacerbated by their exposure to an 'obesogenic' diet. Physiological Reports 3 e12336. (doi:10.14814/ phy2.12336)

Gao Y \& Sun T 2016 Molecular regulation of hypothalamic development and physiological functions. Molecular Neurobiology 53 4275-4285. (doi:10.1007/s12035-015-9367-z)

Gavrila A, Chan JL, Miller LC, Heist K, Yiannakouris N \& Mantzoros CS 2005 Circulating melanin-concentrating hormone, agouti-related protein, and alpha-melanocyte-stimulating hormone levels in relation to body composition: alterations in response to food deprivation and recombinant human leptin administration. Journal of Clinical Endocrinology and Metabolism 90 1047-1054. (doi:10.1210/jc.20041124)

Ghanayem BI, Bai R, Kissling GE, Travlos G \& Hoffler U 2010 Dietinduced obesity in male mice is associated with reduced fertility and potentiation of acrylamide-induced reproductive toxicity. Biology of Reproduction 82 96-104. (doi:10.1095/biolreprod.109.078915)

Godfrey KM, Reynolds RM, Prescott SL, Nyirenda M, Jaddoe VW, Eriksson JG \& Broekman BF 2017 Influence of maternal obesity on the longterm health of offspring. Lancet Diabetes and Endocrinology 5 53-64. (doi:10.1016/S2213-8587(16)30107-3)

Gregor MF \& Hotamisligil GS 2011 Inflammatory Mechanisms in Obesity. Annual Review of Immunology 29 415-445. (doi:10.1146/annurevimmunol-031210-101322)

Jaacks LM, Siegel KR, Gujral UP \& Narayan KMV 2016 Type 2 diabetes: a 21st century epidemic. Best Practice and Research: Clinical Endocrinology and Metabolism 30 331-343. (doi:10.1016/j. beem.2016.05.003)

Kageyama H, Takenoya F, Hirako S, Wada N, Kintaka Y, Inoue S, Ota E, Ogawa T \& Shioda S 2012 Neuronal circuits involving neuropeptide $\mathrm{Y}$ in hypothalamic arcuate nucleus-mediated feeding regulation. Neuropeptides 46 285-289. (doi:10.1016/j.npep.2012.09.007)

Kalinovich AV, de Jong JM, Cannon B \& Nedergaard J 2017 UCP1 in adipose tissues: two steps to full browning. Biochimie 134 127-137. (doi:10.1016/j.biochi.2017.01.007)

Kivimäki M, Lawlor DA, Smith GD, Elovainio M, Jokela M, Keltikangas-Järvinen L, Viikari JS \& Raitakari OT 2007 Substantial intergenerational increases in body mass index are not explained by the fetal overnutrition hypothesis: the Cardiovascular Risk in Young Finns Study. American Journal of Clinical Nutrition 86 1509-1514.

Kwon O, Kim KW \& Kim MS 2016 Leptin signalling pathways in hypothalamic neurons. Cellular and Molecular Life Sciences $\mathbf{7 3}$ 1457-1477. (doi:10.1007/s00018-016-2133-1)

Lage R, Fernø J, Nogueiras R, Diéguez C \& López M 2016 Contribution of adaptive thermogenesis to the hypothalamic regulation of energy balance. Biochemical Journal 473 4063-4082. (doi:10.1042/ BCJ20160012) http://joe.endocrinology-journals.org

DOI: $10.1530 / J O E-17-0082$
๑ 2017 Society for Endocrinology Printed in Great Britain 
Lane RH 2014 Fetal programming, epigenetics, and adult onset disease. Clinics in Perinatology 41 815-831. (doi:10.1016/j.clp.2014.08.006)

Lenzen S 2008 The mechanisms of alloxan- and streptozotocininduced diabetes. Diabetologia 51 216-226. (doi:10.1007/s00125007-0886-7)

Loh K, Herzog H \& Shi YC 2015 Regulation of energy homeostasis by the NPY system. Trends in Endocrinology and Metabolism 26 125-135. (doi:10.1016/j.tem.2015.01.003)

Masuyama H, Mitsui T, Eguchi T, Tamada S \& Hiramatsu Y 2016 The effects of paternal high-fat diet exposure on offspring metabolism with epigenetic changes in the mouse adiponectin and leptin gene promoters. American Journal of Physiology: Endocrinology and Metabolism 311 E236-E245. (doi:10.1152/ajpendo.00095.2016)

McCurdy CE, Bishop JM, Williams SM, Grayson BE, Smith MS, Friedman JE \& Grove KL 2009 Maternal high-fat diet triggers lipotoxicity in the fetal livers of nonhuman primates. Journal of Clinical Investigation 119 323-335. (doi:10.1172/JCI32661)

Mitchell M, Bakos HW \& Lane M 2011 Paternal diet-induced obesity impairs embryo development and implantation in the mouse. Fertility and Sterility 95 1349-1353. (doi:10.1016/j.fertnstert.2010.09.038)

Mouralidarane A, Soeda J, Visconti-Pugmire C, Samuelsson A-M, Pombo J, Maragkoudaki X, Butt A, Saraswati R, Novelli M, Fusai G, et al. 2013 Maternal obesity programs offspring nonalcoholic fatty liver disease by innate immune dysfunction in mice. Hepatology 58 128-138. (doi:10.1002/hep.26248)

Ng S-F, Lin RCY, Laybutt DR, Barres R, Owens JA \& Morris MJ 2010 Chronic high-fat diet in fathers programs beta-cell dysfunction in female rat offspring. Nature 467 963-963. (doi:10.1038/nature09491)

Nillni EA 2016 The metabolic sensor Sirt1 and the hypothalamus: Interplay between peptide hormones and pro-hormone convertases. Molecular and Cellular Endocrinology 438 77-88. (doi:10.1016/j.mce.2016.09.002)

Nivoit P, Morens C, Van Assche FA, Jansen E, Poston L, Remacle C \& Reusens B 2009 Established diet-induced obesity in female rats leads to offspring hyperphagia, adiposity and insulin resistance. Diabetologia 52 1133-1142. (doi:10.1007/s00125-009-1316-9)

Ornellas F, Souza-Mello V, Mandarim-de-Lacerda CA \& Aguila MB 2015 Programming of obesity and comorbidities in the progeny: lessons from a model of diet-induced obese parents. PLOS ONE 10 e0124737. (doi:10.1371/journal.pone.0124737)

Roh E, Song dK \& Kim MS 2016 Emerging role of the brain in the homeostatic regulation of energy and glucose metabolism. Experimental and Molecular Medicine $\mathbf{4 8}$ e216. (doi:10.1038/emm.2016.4)

Samuelsson A-M, Matthews PA, Argenton M, Christie MR, McConnell JM, Jansen EHJM, Piersma AH, Ozanne SE, Twinn DF, Remacle C, et al. 2008 Diet-induced obesity in female mice leads to offspring hyperphagia, adiposity, hypertension, and insulin resistance - a novel murine model of developmental programming. Hypertension 51 383-392. (doi:10.1161/HYPERTENSIONAHA.107.101477)

Shi YC, Lau J, Lin Z, Zhang H, Zhai L, Sperk G, Heilbronn R, Mietzsch M, Weger S, Huang XF, et al. 2013 Arcuate NPY controls sympathetic output and BAT function via a relay of tyrosine hydroxylase neurons in the PVN. Cell Metabolism 17 236-248. (doi:10.1016/j.cmet.2013.01.006)
Sidossis L \& Kajimura S 2015 Brown and beige fat in humans: thermogenic adipocytes that control energy and glucose homeostasis. Journal of Clinical Investigation 125 478-486. (doi:10.1172/JCI78362)

Song Y, Li J, Zhao Y, Zhang Q, Liu Z, Li J, Chen X, Yang Z, Yu C \& Xiao X 2012 Severe maternal hyperglycemia exacerbates the development of insulin resistance and fatty liver in the offspring on high fat diet. Experimental Diabetes Research 2012254976. (doi:10.1155/2012/254976)

Soubry A, Schildkraut JM, Murtha A, Wang F, Huang Z, Bernal A, Kurtzberg J, Jirtle RL, Murphy SK \& Hoyo C 2013 Paternal obesity is associated with IGF2 hypomethylation in newborns: results from a Newborn Epigenetics Study (NEST) cohort. BMC Medicine 1129. (doi:10.1186/1741-7015-11-29)

Sullivan EL, Rivera HM, True CA, Franco JG, Baquero K, Dean TA, Valleau JC, Takahashi DL, Frazee T, Hanna G, et al. 2017 Maternal and postnatal high-fat diet consumption programs energy balance and hypothalamic melanocortin signaling in nonhuman primate offspring. American Journal of Physiology: Regulatory Integrative and Comparative Physiology. (doi:10.1152/ajpregu.00309.2016)

Tesch GH \& Allen TJ 2007 Rodent models of streptozotocin-induced diabetic nephropathy. Nephrology 12 261-266. (doi:10.1111/j.14401797.2007.00796.x)

Wang H, Ji J, Yu Y, Wei X, Chai S, Liu D, Huang D, Li Q, Dong Z \& Xiao X 2015 Neonatal overfeeding in female mice predisposes the development of obesity in their male offspring via altered central leptin signalling. Journal of Neuroendocrinology 27 600-608. (doi:10.1111/jne.12281)

Wei Y, Yang C-R, Wei Y-P, Zhao Z-A, Hou Y, Schatten H \& Sun Q-Y 2014 Paternally induced transgenerational inheritance of susceptibility to diabetes in mammals. PNAS 111 1873-1878. (doi:10.1073/ pnas.1321195111)

Wells JC 2014 Commentary: paternal and maternal influences on offspring phenotype: the same, only different. International Journal of Epidemiology 43 772-774. (doi:10.1093/ije/dyu055)

Westerterp KR 2013 Metabolic adaptations to over - and underfeeding - still a matter of debate? European Journal of Clinical Nutrition 67 443-445. (doi:10.1038/ejcn.2012.187)

Williams DL \& Schwartz MW 2011 Neuroanatomy of body weight control: lessons learned from leptin. Journal of Clinical Investigation 121 2152-2155. (doi:10.1172/JCI58027)

Wu L, Lu Y, Jiao Y, Liu B, Li S, Li Y, Xing F, Chen D, Liu X, Zhao J, et al. 2016 Paternal psychological stress reprograms hepatic gluconeogenesis in offspring. Cell Metabolism 23 735-743. (doi:10.1016/j.cmet.2016.01.014)

Xu Y, Nedungadi TP, Zhu L, Sobhani N, Irani BG, Davis KE, Zhang X, Zou F, Gent LM, Hahner LD, et al. 2011 Distinct hypothalamic neurons mediate estrogenic effects on energy homeostasis and reproduction. Cell Metabolism 14 453-465. (doi:10.1016/j. cmet.2011.08.009)

Zandian M, Ioakimidis I, Bergh C, Leon M \& Södersten P 2011 A sex difference in the response to fasting. Physiological Behavior 103 530-534. (doi:10.1016/j.physbeh.2011.04.009)

Received in final form 17 May 2017

Accepted 19 May 2017

Accepted Preprint published online 22 May 2017 http://joe.endocrinology-journals.org

DOI: 10.1530/JOE-17-0082
() 2017 Society for Endocrinology Printed in Great Britain
Published by Bioscientifica Ltd. 